\title{
PANCREATITE AGUDA: ATUALIZAÇÃO DE CONCEITOS E CONDUTAS
}

\author{
ACUTE PANCREATITIS: REVIEW OF CONCEPTS AND MANAGEMENT
}

José Sebastião dos Santos ${ }^{1}$; Jorge Elias Júnior ${ }^{2}$; Sandro Scarpelini ${ }^{1}$ \& Ajith K. Sankarankutty ${ }^{1}$

${ }^{1}$ Docentes. Departamento de Cirurgia e Anatomia; ${ }^{2}$ Docente. Departamento de Clínica Médica. Faculdade de Medicina de Ribeirão Preto-USP.

CorResPondêncIA: Prof. Dr. José Sebastião dos Santos. Departamento de Cirurgia e Anatomia. Faculdade de Medicina de Ribeirão Preto - USP.Av. Bandeirantes, 3900, Campus Universitário. CEP: 14048-900 - Ribieirão Preto - SP - Brasil. e-mail jsdsanto@fmrp.usp.br

SANTOS JS; ELIAS JÚNIOR E; SCARPELINI S \& SANKARANKUTTY AK. Pancreatite aguda: atualização de conceitos e condutas. Medicina, Ribeirão Preto, 36: 266-282, abr./dez. 2003.

RESUMO - A abordagem diagnóstica e terapêutica da pancreatite aguda (PA) modificou-se significativamente, nos últimos 20 anos. A revisão da literatura reforça a importância de estratificar a PA em formas branda e grave, com o objetivo de definir o local e os recursos para o tratamento. Há evidências recentes, que ajudaram a definir o papel da tomografia computadorizada (TC), da colangiopancreatografia endoscópica (CPRE), da ressonância magnética $(R M)$, da antibioticoterapia profilática, do suporte nutricional enteral e da punção com agulha fina, para exame bacteriológico de material necrótico e de fluido pancreático. Houve mudança significativa na abordagem cirúrgica da PA; as operações, que eram extensas e freqüentes na fase precoce, deram lugar a uma conduta mais conservadora, exceto quando o diagnóstico de necrose pancreática infectada é confirmado. Os protocolos de consenso recomendam a detecção precoce das complicações por meio da avaliação clínica e de imagem. O emprego apropriado das alternativas terapêuticas, clínicas e cirúrgicas, com base na evidência, pode garantir a redução da morbidade e da mortalidade na PA.

UNITERMOS - Pancreatite Aguda. Pancreatite. Monitoramento. Pancreatite Aguda Necrosante. Nutrição; cirurgia; tratamento.

\section{INTRODUÇÃO}

A pancreatite aguda (PA) é, na maioria dos casos, uma doença inflamatória, autolimitada e que se resolve com medidas clínicas. Todavia, a presença de necrose pancreática e peripancreática, associada à infecção, é potencialmente grave e pode demandar cuidados e abordagens especializadas. A incidência de PA, baseada em registros hospitalares, varia de 5,4 a 79,8 casos por 100.000 habitantes, respectivamente, na Inglaterra e nos Estados Unidos da América ${ }^{(1)}$. A avaliação da incidência da PA é prejudicada pela falta de confirmação histológica na maioria dos casos e, possivelmente, reflete a organização dos serviços de saúde. É provável que muitos pacientes com PA na forma branda não procurem os serviços de saúde ou, quando o fazem, os casos não são diagnosticados ou notificados $^{(2)}$.

A mortalidade global, na PA, varia de 10 a $15 \%{ }^{(3)}$. Dentre os óbitos, cerca de $50 \%$ ocorrem na fase precoce, isto é, nos primeiros 14 dias da admissão, e decorrem, principalmente, da síndrome da resposta inflamatória sistêmica, secundária à necrose pancreática, enquanto os óbitos remanescentes ocorrem na fase tardia, em função de complicações infecciosas, também da necrose pancreática ${ }^{(4)}$. 
A PA é uma doença associada ou determinada por problemas congênitos, hereditários e adquiridos, ou por agentes de natureza química, traumática e infecto-parasitária e, embora comporte diversos mecanismos etiopatogênicos, o evento final é a ativação das enzimas pancreáticas no interior das células acinares ${ }^{(5)}$. Em cerca de $85 \%$ a $90 \%$ dos casos, a doença tem um componente apenas de inflamação pancreática e apresenta-se com mínima disfunção orgânica, com taxas de mortalidade, em geral, inferiores a $2 \%{ }^{(6)}$. Em aproximadamente $10 \%$ dos casos, além do componente inflamatório, ocorre necrose no parênquima pancreático e nos tecidos adjacentes, o que pode evoluir com infecção e, mais raramente, com as complicações isquêmicas, obstrutivas, perfurativas e hemorrágicas das vísceras circunvizinhas. Essas alterações locorregionais são acompanhadas de repercussões sistêmicas maiores, que podem evoluir com a falência de órgãos e sistemas e a morte, cujas taxas, nessas circunstâncias, são muito elevadas e variam de 20 a $70 \%{ }^{(6)}$.

A magnitude das lesões pancreáticas, geralmente, correlaciona-se com a gravidade da doença, e é possível, nos dois primeiros dias da admissão, com base na apresentação clínica, na avaliação laboratorial de rotina e no exame tomográfico, classificar a doença em branda ou grave ${ }^{(7)}$. Na forma branda, que inclui a grande maioria dos casos, as manifestações cursam com mínima repercussão sistêmica, que melhora com a reposição de líquidos e eletrólitos. O tratamento pode ser feito nas enfermarias de medicina interna e a doença resolve-se em, aproximadamente, uma semana.

Por outro lado, na forma grave, além das complicações locais, há falência de órgãos e sistemas dis- tantes, o que, via de regra, não responde às medidas iniciais. Assim, o tratamento na dependência do monitoramento e dos procedimentos poderá ser feito nas salas de estabilização clínica, nos centros de terapia intensiva e nas enfermarias de clínica cirúrgica, e ter duração de semanas ou meses.

A PA é o quinto diagnóstico etiológico de abdômen agudo mais registrado nas salas de urgência de hospitais de referência e a quarta causa de internação por abdômen agudo, em tais serviços ${ }^{(8)}$. A abordagem da PA contempla, na medida do possível, os conhecimentos acumulados e sistematizados no Simpósio Internacional de Atlanta, em 1992 ${ }^{(7)}$, em conferências de consenso ${ }^{(9,10)}$, bem como em resultados de investigações planejadas e de observações retrospectivas, avaliadas com base na evidência.

A investigação clínica, a estratificação da PA e as diretrizes terapêuticas a serem adotadas são orientadas, inicialmente, pela identificação das condições associadas à doença e pela avaliação das condições clínicas iniciais, considerando o impacto sobre as funções vitais e o metabolismo sistêmico. Na seqüência, de forma seletiva, são indicadas as dosagens séricas dos marcadores da lesão pancreática, do envolvimento das vias biliares e da repercussão sistêmica da doença, assim como a avaliação por imagem do pâncreas, por meio da TC e, mais recentemente, através da $\mathrm{RM}$, para os casos de PA aguda, de origem biliar $^{(8,11)}$.

\section{ETIOPATOGENIA}

Dentre as principais causas de PA, estão a passagem de cálculo pelo ducto biliar comum e o excesso de ingestão alcoólica, que, juntos, correspondem a aproximadamente $80 \%$ dos $\operatorname{casos}^{(12)}$. (Tabela I)

Tabela I - Causas de pancreatite aguda (modificada de Beckingham \& Bornman, 2001)

\section{Causas}

Litíase e microlitíase biliar, Abuso da ingestão de álcool

Idiopáticas

\section{Freqüiência}

$80 \%$

$10 \%$

\section{Outras}

Drogas,Trauma, Cirurgia abdominal, Bypass cardiopulmonar, Hipercalcemia, Hiperlipidemia,Úlcera péptica penetrante, Vasculite, Tumores pancreáticos, Pâncreas divisum, Pancreatite familiar, Isquemia ou Embolia, Gravidez, Transplante de órgãos, Insuficiência renal avançada, Prasitas intraductais (áscaris), Infecção por Mycoplasma, Venenos de algumas espécies de aranha e escorpião, Infecção viral (caxumba, coxsackie B, vírus da imunodeficiência humana adquirida, dentre outras) 
As tentativas de estabelecer o nexo entre as condições associadas referidas e o início do desenvolvimento da PA ainda são controversas. Acreditavase que a ativação enzimática dar-se-ia no interior do ducto pancreático ou nos espaços intercelulares, mas investigações posteriores sugerem que a ativação da tripsina ocorra dentro das células acinares. Em situações normais, as enzimas digestivas e lisossômicas ficam segregadas nos grânulos de zimogênio e nos lisossomos, respectivamente. Em modelos experimentais, o estágio inicial da pancreatite consiste na mistura das enzimas digestivas e lisossômicas. Especula-se, se a obstrução biliopancreática, os refluxos biliar e duodenal para o ducto pancreático, o álcool, as drogas, os produtos lipídicos e a isquemia podem causar distúrbios na função das células acinares, induzindo, então, a ativação da tripsina intracelular, pela fusão dos lisossomos com os grânulos de zimogênio ${ }^{(5)}$.

As lesões que podem ocorrer na PA são as seguintes: a) coleções agudas: ocorrem precocemente, e estão localizadas ao redor do pâncreas, no próprio órgão, e não têm parede formada por tecido de granulação ou fibrose; b) necrose pancreática: área difusa ou focal de parênquima pancreático, não viável, que se associa à necrose da gordura peripancreática, podendo ser estéril ou infectada; c) pseudocisto pancreático: coleção de suco pancreático com parede fibrosa ou tecido de granulação, que pode decorrer da PA, do trauma pancreático e da pancreatite crônica, e demora, para se formar, pelo menos, quatro semanas, a partir do início do processo; d) abscesso pancreático: coleção purulenta, localizada nas proximidades do pâncreas, com pouca ou nenhuma necrose pancreática, e que se origina da PA ou do trauma pancreático ${ }^{(7)}$.

\section{APRESENTAÇÃO CLÍNICA}

A experiência e os conhecimentos acumulados e sistematizados demonstram que, independente das condições associadas, a PA tem duas possíveis histórias naturais para cada episódio ou existem duas formas de apresentação da doença: uma com resolução rápida, em aproximadamente uma semana, e outra, prolongada, que dura semanas ou meses, com intercorrências locais e sistêmicas, que poderão ser resolvidas, culminar com a morte ou deixar seqüelas. Assim, a estratificação dos pacientes, quanto à forma de apresentação, em pancreatite branda e grave, auxilia na orientação da terapêutica e na comparação dos resultados.
Não há quadro patognomônico de PA. Os pacientes acometidos, em geral, estão na faixa dos 30 aos 60 anos. Na maioria dos casos, o diagnóstico é baseado na presença de dor abdominal e indicadores bioquímicos de lesões pancreáticas, o que é limitante. $\mathrm{O}$ exame direto do pâncreas, que poderia fornecer diagnóstico de certeza, raramente é realizado ${ }^{(2)}$.

O sintoma inicial, e predominante, é a dor, embora, eventualmente, possa estar ausente. $\mathrm{O}$ aparecimento é repentino, a localização é epigástrica, com irradiação para flancos e dorso ${ }^{(12)}$. A dor é constante, pode ser intensa e precipitada por ingestão excessiva de álcool ou alimentos. A melhora pode ser obtida com decúbito lateral e a flexão das coxas sobre o abdômen, além da aspiração gástrica e jejum ${ }^{(2,8)}$ (Tabela II).

As náuseas e os vômitos são freqüentes e precoces. Os vômitos podem ser de natureza reflexa ou por compressão duodenal pelo pâncreas edemaciado. Às vezes, ocorre parada de eliminação de gases e fezes e, ocasionalmente, dispnéia ${ }^{(2,8)}$.

A PA indolor é rara; nessa apresentação, o prognóstico é grave, visto que os pacientes, freqüentemente, estão em choque circulatório ou coma. Em alguns casos graves e fatais, a PA é diagnosticada apenas durante a necrópsia ${ }^{(13)}$.

Ao exame físico, nos casos mais graves, o paciente está em sofrimento, com sudorese, e pode haver icterícia e cianose. A temperatura, na maioria das vezes, é normal, mas pode ocorrer febre em decorrência, provavelmente, de produtos da lesão tecidual, lançados na circulação, assim como hipotermia conseqüente à adinamia circulatória. Curva febril séptica sugere o desenvolvimento de infecção bacteriana na forma de abcesso pancreático, pneumonia, colecistite ou colangite ${ }^{(2,8)}$.

A hipertensão arterial, se presente, ocorre na fase inicial e é transitória. Na pancreatite grave, há taquicardia, a hipotensão arterial é freqüente, e, às vezes, acompanhada de choque circulatório. Em alguns pacientes com pancreatite grave, a hipotensão e a hipoperfusão persistem, apesar da reposição volêmica. Nesses pacientes, o débito cardíaco é elevado e a resistência periférica é baixa. Esses achados são similares aos observados em pacientes com sepse e cirrose hepática e são atribuídos à liberação de cininas vasoativas, que promovem vasodilatação e aumento da permeabilidade vascular ${ }^{(14)}$.

A falência cardiovascular é determinada pela hipovolemia, decorrente da perda de fluidos pelos vômitos, pela febre e pelo seqüestro no intestino, na região peripancreática e no retroperitôneo ${ }^{(2,8,15)}$. 
Na apresentação inicial, há hipersensibilidade e dor localizada à palpação profunda; os sinais de irritação peritoneal, como rigidez de parede abdominal e dor à descompressão, estão ausentes, sobretudo na PA branda, em função da localização retroperitoneal do pâncreas ${ }^{(8)}$. O aparecimento dos sinais de comprometimento peritoneal dar-se-á com a progressão das lesões pancreáticas.

Pode existir plastrão palpável, doloroso, no epigástrio, nos casos com envolvimento locorregional grave. A pigmentação esverdeada ou preta, nas regiões lombares (sinal de Grey-Turner) ou na região umbilical (sinal de Halsted), decorrente da dissecção do tecido retroperitoneal por hemorragia, é rara e só aparece depois de vários dias. Os ruídos intestinais estão diminuídos e, nos primeiros dias, há distensão abdominal discreta. O íleo paralítico completo denota disseminação do processo inflamatório para o mesentério do intestino delgado e do cólon, ou peritonite química, provocada por ascite pancreática ${ }^{(2,8)}$.

A tetania hipocalcêmica é rara e indicativa de prognóstico ruim. A ocorrência de necrose gordurosa do subcutâneo, principalmente das extremidades, assemelhando-se ao eritema nodoso, é rara, e aparece num estágio mais tardio da doença. A hiperbilirrubinemia leve é decorrente da compressão extrínseca do ducto biliar comum, terminal pelo pâncreas $(<2,5 \mathrm{mg} / \mathrm{dl})$. Quando há impactação de cálculo, no ducto biliar comum, a concentração de bilirrubina, em geral, é maior que $2,5 \mathrm{mg} / \mathrm{dl}^{(2,14)}$.

A porção medial do duodeno e a curvatura maior do antro podem ser afetadas diretamente pela inflamação, podendo resultar, embora raramente, em obstrução digestiva e hemorragia ${ }^{(2)}$.

A ventilação pulmonar pode estar comprometida pela dor abdominal pleurítica, por atelectasia e por derrames pleurais exsudativos, quase sempre hemorrágicos e ricos em amilase e lipase. A irritação do diafragma pode resultar em soluços e dor no ombro ${ }^{(2,8,14)}$.

A hipóxia arterial se desenvolve, na maioria dos pacientes, com pancreatite grave. $\mathrm{A} \mathrm{pO}_{2}$ arterial cai para 50 a $70 \mathrm{mmHg}$, nesses casos, sem qualquer alteração radiológica no início. Nos dias subseqüentes, aparecem infiltrado pulmonar difuso e hipoxemia grave, com instalação da síndrome de angústia respiratória do adulto. A liberação de proteases pancreáticas ativas, na circulação, pode levar à formação de microtrombos, com consumo de fatores de coagulação e componentes do complemento (coagulação intravascular disseminada). Há um desvio intrapulmo-

nar da direita para a esquerda, principal fator de hipóxia. A fosfolipase $\mathrm{A}_{2}$ e as altas concentrações de ácidos graxos livres circulantes alteram a camada de surfactante e produzem edema pulmonar. ${ }^{(16)}$

A oligúria e a anúria são consequiências da hipovolemia e hipoperfusão. Por outro lado, a insuficiência renal também pode se desenvolver em pacientes normovolêmicos; nesses casos, a coagulação intravascular disseminada pode induzir à hipóxia com comprometimento renal ${ }^{(14) \text {. }}$

As alterações neurológicas são freqüentes na pancreatite grave, os pacientes podem estar em estado de coma, em choque circulatório ou com psicose tóxica; o delirium tremens é freqüente nos alcoólatras. ${ }^{(14)}$

Tabela II - Incidência dos sinais e sintomas da pancreatite aguda

\section{Sinal/Sintoma}

Dor abdominal

Irradiação para o dorso

Náuseas/ Vômitos

Febre

Hipotensão arterial

Massa palpável

Icterícia

Adaptado de RANSON JHC. Acute pancreatitis. Current practice of gastrointestinal and abdominal surgery, $1994^{(14)}$

\section{QUADRO LABORATORIAL}

O hemograma, o ionograma, a uréia, a creatinina, a glicemia e a gasometria servem para diagnosticar alterações metabólicas e orientar as respectivas correções $^{(2,8)}$.

$\mathrm{Na}$ avaliação hematológica, observa-se, com frequiência, elevação do hematócrito, na admissão em virtude do sequiestro e perda de líquidos. Com a reposição de fluidos, ocorre a normalização do hematócrito; a queda persistente do hematócrito, abaixo da normalidade, implica em busca de focos hemorrágicos. A leucocitose é freqüente; nas pancreatites graves, pode ocorrer reação leucemóide, mesmo na ausência de infecção ${ }^{(2,8)}$. 
A hiperglicemia leve e transitória é freqüente, sobretudo durante os ataques iniciais, onde a liberação de glucagon, de catecolaminas e de glicocorticóides é maior; entretanto, a persistência de hiperglicemia de jejum, superior a $200 \mathrm{mg} / \mathrm{dl}$ pode refletir a instalação de necrose pancreática ${ }^{(14)}$.

A hipocalcemia pode ser notada por volta do $2^{\circ}$ ou do $3^{\circ}$ dia da instalação da doença e, raramente, é grave. Níveis de cálcio inferiores a 7,0 mg/dl indicam prognóstico ruim ${ }^{(14,15)}$.

Uma queda progressiva da $\mathrm{pO}_{2}$ arterial, que ocorre dentro de vários dias após o início dos sintomas, denota o desenvolvimento da síndrome da Angústia Respiratória do Adulto e edema pulmonar ${ }^{(14)}$.

A azotemia pré-renal, hipocalcemia, hiperglicemia e hipóxia correlacionam-se com a gravidade da doença. Atenção especial deve ser dada aos fatores que alteram o resultado da produção das enzimas tissulares, que afetam a concentração na circulação sangüínea, bem como o seu clareamento ${ }^{(2,15)}$.

Em geral, as grandes elevações dos níveis de enzimas, produzidas no pâncreas, não se correlacionam com a gravidade da PA. A elevação da amilasemia resulta do aumento do extravasamento da enzima na circulação e da redução do clareamento renal ${ }^{(17)}$. Após o início da inflamação pancreática, já nas primeiras horas, a amilase e a lipase sérica elevam-se. Após o ataque, a amilase sérica reduz-se mais rapidamente que a lipase, e retorna à normalidade dentro de $24 \mathrm{~h}$; a elevação persistente da amilase é indício de complicação, como abscesso e pseudocisto. Em alguns pacientes, em que a pancreatite é letal, a amilase pode estar normal, provavelmente, pela grande destruição glandular. A lipase é o melhor indicador de pancreatite em pacientes que são vistos vários dias após o início da crise pancreática ${ }^{(17)}$.

A amilase, também, pode ser detectada nos derrames pleurais e peritoneais pancreáticos, o que pode ser de grande valia. Em geral, nesses derrames, o nível varia de três a 10 vezes a mais que os valores séricos, obtidos simultaneamente ${ }^{(2,8)}$.

$\mathrm{Na} P A$ de etiologia biliar, os testes bioquímicos podem refletir o caráter intermitente ou mantido da obstrução biliar e orientar a terapêutica. A presença de cálculo, na via biliar comum, é acompanhada de elevação da bilirrubina, da fosfatase alcalina e de marcadores da lesão hepatocítica - AST e ALT; há, também, elevação acentuada da amilase, com níveis que atingem de 2.000 a $4.000 \mathrm{UI} / 1$. A persistência da elevação das enzimas canaliculares e hepatocelulares indica permanência dos cálculos na via biliar, enquanto a flutuação sugere obstrução intermitente $\left({ }^{2,8)}\right.$.

\section{EXAMES DE IMAGEM}

As radiografias de tórax e abdômen são exames importantes para excluir causas perfurativas de abdômen agudo. No entanto, uma variedade de achados radiográficos está associada à pancreatite ${ }^{(14)}$ (Tabela III).

\begin{tabular}{l|c|}
\hline $\begin{array}{l}\text { Tabela III - Incidência dos sinais radiográficos suges- } \\
\text { tivos de pancreatite }\end{array}$ \\
\hline Sinal Radiográfico & Incidência (\%) \\
\hline “Alça sentinela" & 41 \\
\hline Dilatação do cólon transverso & 22 \\
\hline Apagamento do psoas & 19 \\
\hline $\begin{array}{l}\text { Velamento no andar superior do } \\
\text { abdômen }\end{array}$ & 19 \\
\hline $\begin{array}{l}\text { Aumento da distância entre cólon e } \\
\text { estômago }\end{array}$ & 15 \\
\hline $\begin{array}{l}\text { Distorção da curvatura maior do } \\
\text { estômago }\end{array}$ & 14 \\
\hline Distensão gasosa do duodeno & 11 \\
\hline Efusão pleural & 04 \\
\hline Calcificação pancreática & 03 \\
\hline $\begin{array}{l}\text { Um ou mais sinais listados } \\
\text { gastrointestinal and abdominal surgery, 1994 (14) }\end{array}$ & practice of \\
\hline RANSON JHC. Acute pancreatitis. Current & 79 \\
\hline
\end{tabular}

As radiografias convencionais de abdômen e os estudos contrastados do tubo digestivo são, ocasionalmente, úteis para ajudar no diagnóstico de PA e para demonstrar complicações relacionadas, tais como abscessos (Figura 1) e estreitamentos de alça intestinal ou fístulas, mas não têm indicação na estratificação da gravidade.

A ultra-sonografia (US) tem pouco valor na avaliação do pâncreas, na estratificação da PA e na detecção de necrose pancreática; a presença de gases intestinais e a obesidade são fatores limitantes para a acurácia do exame ultra-sonográfico, em comparação à tomografia. A US é um exame para o início da avaliação da pancreatite leve e tem grande valor no 


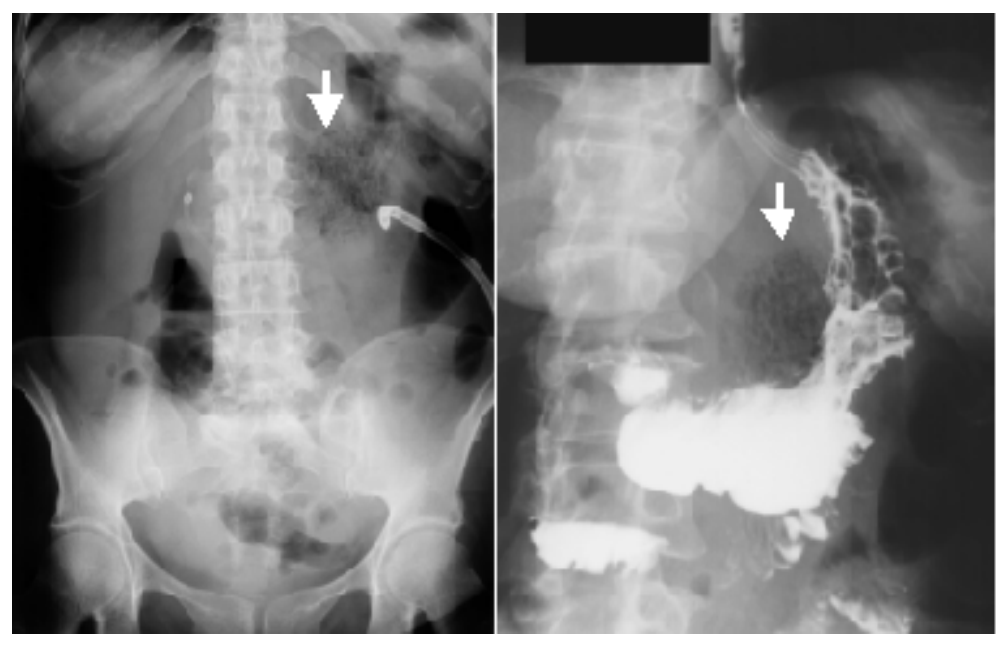

Figura 1 - Radiografia simples de abdômen (E) e seriografia de estômago (D), demonstrando abscesso pancreático com gás no interior (seta).

Fonte: Centro de Ciências das Imagens e Física Médica do Hospital das Clínicas da Faculdade de Medicina de Ribeirão Preto-USP (CCIFM-HC-FMRP-USP)

A US também pode demonstrar a extensão extrapancreática da inflamação, envolvendo o espaço pararenal anterior, o mesocólon transverso e a retrocavidade dos epíplons ${ }^{(19)}$. As alterações ecográficas da PA são exemplificadas na Figura 2.

A US também é útil no seguimento evolutivo de coleções e de pseudocistos (Figura 3) e, com a utilização do Doppler, pode auxiliar no diagnóstico de complicações vasculares, tais como pseudoaneurismas e trombose venosa. Devido à facilidade em seu transporte, a US é muito empregada nos casos graves, quando o paciente não pode ser deslocado até a sala de tomografia ${ }^{(20)}$.

A endoultrasonografia, quando disponível, pode ser alternativa recomendada a pacientes com PA biliar e colestase, nas situações em que a US tran-

exame das vias biliares: diagnóstico de cálculos, barro biliar, dilatação das vias biliares, espessamento da parede vesicular ${ }^{(18)}$ Se a distensão vesicular, secundária ao jejum e à presença de gases, dificultar a identificação dos cálculos, faz-se necessário repetir o exame. sabdominal e a tomografia falham na detecção de cálculos na via biliar, ou quando a tomografia e a RM não podem ser realizadas, por exemplo, na presença de implantes metálicos, em mulheres gestantes e em pacientes que não podem sair do centro de terapia intensiva ${ }^{(21)}$.

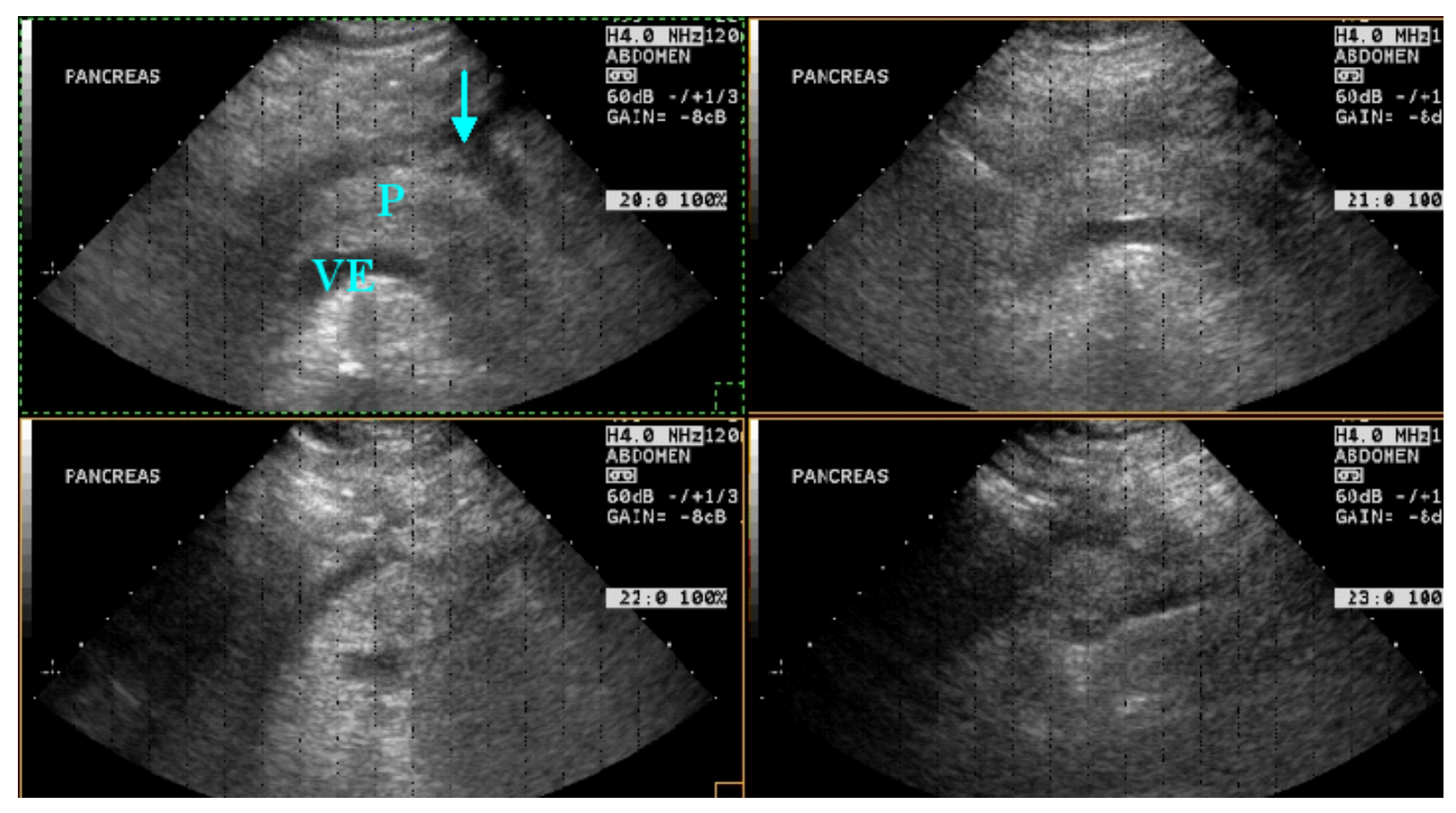

Figura 2 - Pancreatite aguda. Aumento das dimensões do pâncreas $(P)$ com borramento de seus contornos e pequena coleção peripancreática (seta). VE = veia esplênica. Fonte: CCIFM-HC-FMRP-USP 

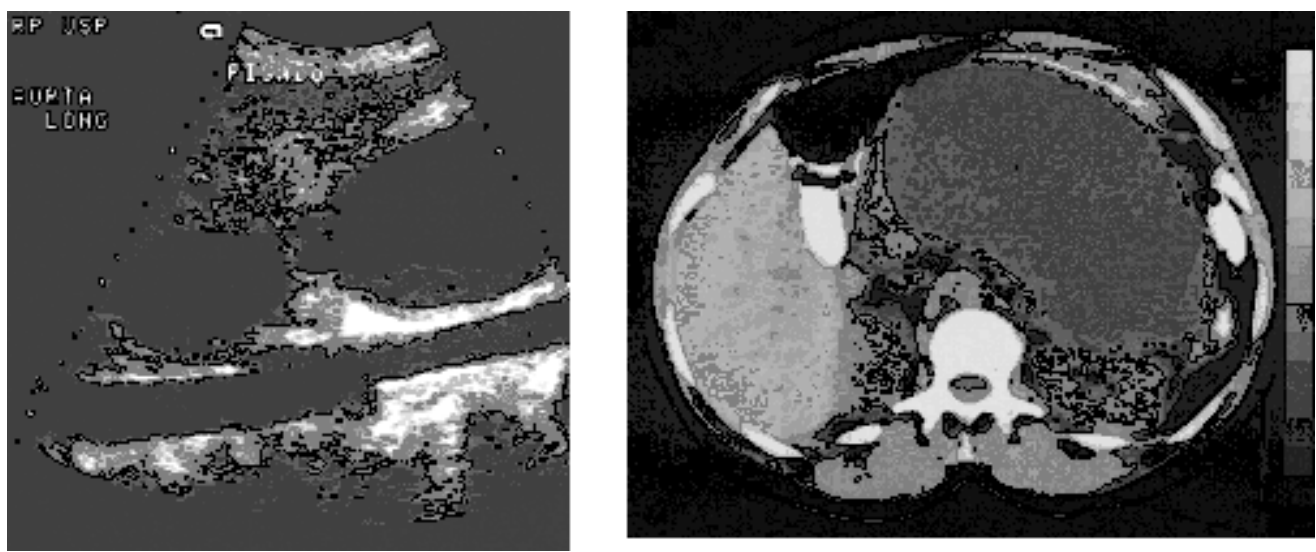

Figura 3 - Dois casos com pseudocistos de pâncreas (P). À direita US demonstra dois pseudocistos anteriores à aorta abdominal, em topografia subepática, peripancreática, com debris no seu interior. À esquerda nota-se corte tomográfico no abdômen superior, com pseudocisto intrapancreático (setas). Fonte: CCIFM-HC-FMRP-USP

A TC é o melhor exame de imagem para diagnosticar as lesões pancreáticas e estratificar a doença que, associada à condição clínica do paciente, permite diagnosticar complicações, como a necrose, e mostra detalhes anatômicos, para orientar punções, aspirações e intervenção cirúrgica, quando indicadas.

As situações clínicas, na PA, que demandam a realização da TC dinâmica com contraste iodado são: a) casos com diagnóstico clínico duvidoso; b) nos pacientes com hiperamilasemia e PA grave, distensão abdominal, febre alta e leucocitose; c) pacientes com índice de Ranson maior que 3 ou o Acute Physiology and Chronic Health Evaluation (APACHE II) maior ou igual a 8; d) casos que não apresentam melhora rápida, nas primeiras $72 \mathrm{~h}$, com tratamento conservador; e) pacientes que apresentam melhora inicial e, posteriormente, têm mudança abrupta do quadro, com piora clínica, indicando o desenvolvimento de complicações locais ${ }^{(22)}$.

Os pacientes com a doença edematosa ao exame inicial, em geral, apresentam apenas discreto aumento da glândula (Figura 4); quando a doença é grave, comumente, há anormalidades pancreáticas e peripancreáticas, como necrose pancreática (Figura 5), acúmulo de líquido pancreático e extrapancreático (Figura 6), e formação de abscesso (Figura 7). A chamada TC pancreatográfica, seqüencial, dinâmica, em que o contraste iodado é injetado via EV, em bolo, com aquisição rápida das imagens, pode ser utilizada com propriedade, para identificar a necrose e sua extensão. $\mathrm{O}$ grau de atenuação é baixo pela hipoperfusão, nas áreas de necrose pancreática; esse achado indica quais são os pacientes que apresentam maior risco de infecção, podem necessitar de acompanhamento clínico minucioso, repetição do exame, e, eventualmente, procedimentos de aspiração, drenagem ou tratamento cirúrgico. A TC não é um exame necessário na PA branda, mas está indicada para avaliar as complicações da PA grave ou quando há dúvida no diagnóstico ${ }^{(22)}$. 


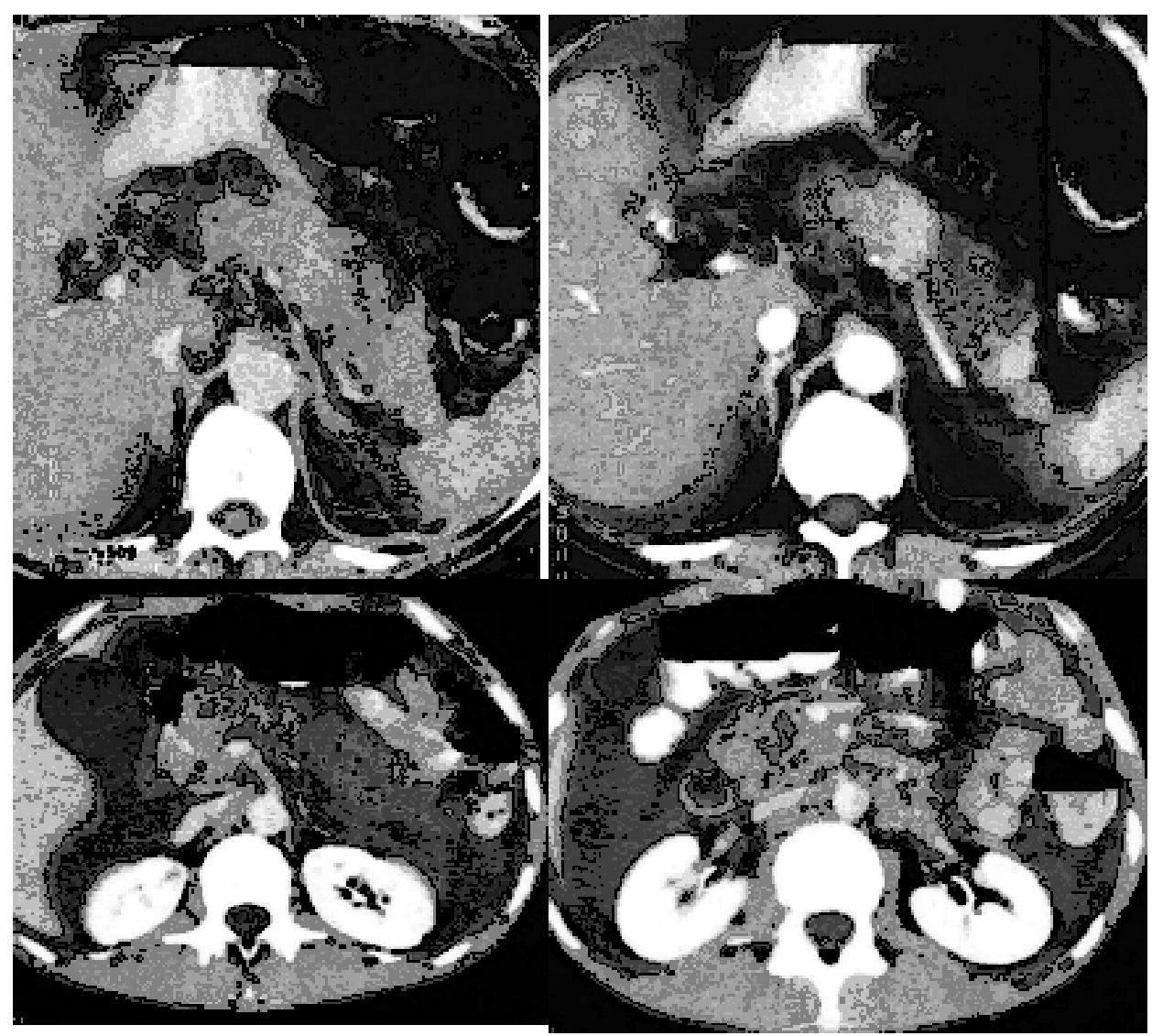

Figura 5 - TC pós-contraste. Os dois cortes axiais superiores são de PA, com necrose glandular menor que $30 \%$, enquanto que os de baixo são de necrose maior que $50 \%$. A área que não se reforça, no parênquima pancreático, corresponde a necrose (setas). Fonte: CCIFM-HC-FMRP-USP

A

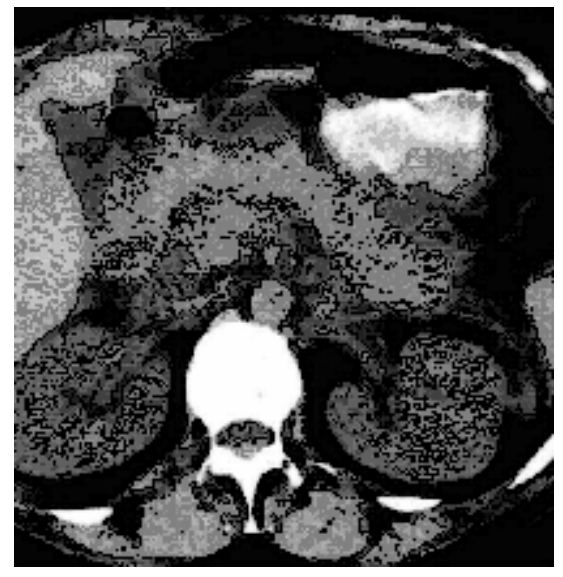

B

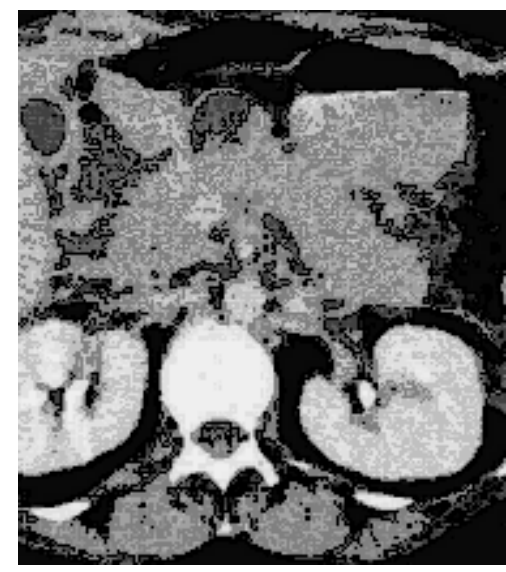

Figura 6 - PA biliar, com pequena coleção junto ao corpo do pâncreas, tanto na fase pré (A) como na pós-contraste intravenoso (B). Fonte: CCIFM-HC-FMRP-USP 

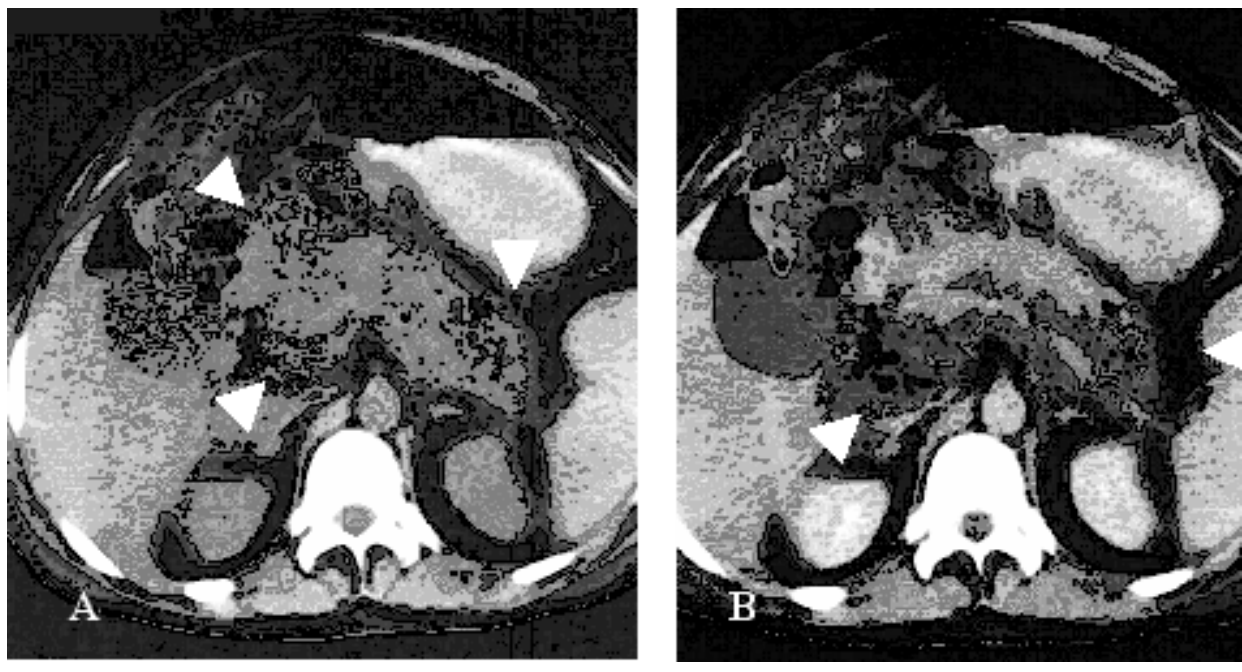

Figura 7 - Necrose pancreática, infectada com abscesso peripancreático. TC sem (A) e com (B) contraste. As pontas de seta mostram imagens de gás. Fonte: CCIFM-HC-FMRP-USP

A colangiopancreatografia retrógrada endoscópica (CPRE) não está indicada na PA biliar leve e na PA não biliar $^{(23)}$. O benefício da CPRE, na PA biliar com colestase e colangite, está bem definido, enquanto o papel, na PA biliar grave, sem obstrução biliar, é motivo de controvérsia ${ }^{(21)}$.

A colangiopancreatografia por ressonância magnética (CPRM) é um exame simples, não invasivo, não requer meio de contraste e tem a mesma eficiência que a CPRE. Assim, tem sido uma alternativa à CPRE, para diagnóstico da obstrução biliar na PA ${ }^{(24)}$ (Figura 8).

Os estudos que comparam a TC com a CPRM têm demonstrado que a última é segura e similar, se não melhor que a TC, para o diagnóstico e a estratificação da $\mathrm{PA}^{(11,25)}$. Ademais, deve ser considerada como método de investigação nos casos em que a etiologia da PA já está definida como biliar ${ }^{(11)}$. No nosso meio, demonstrou-se uma alta correlação entre os achados da TC e da RM, nos casos de PA para a estratificação de gravidade, e tem sido preconizado o emprego da RM com CPRM naqueles casos em que está contra-indicada a utilização de contraste iodado endovenoso ${ }^{(11)}$. A

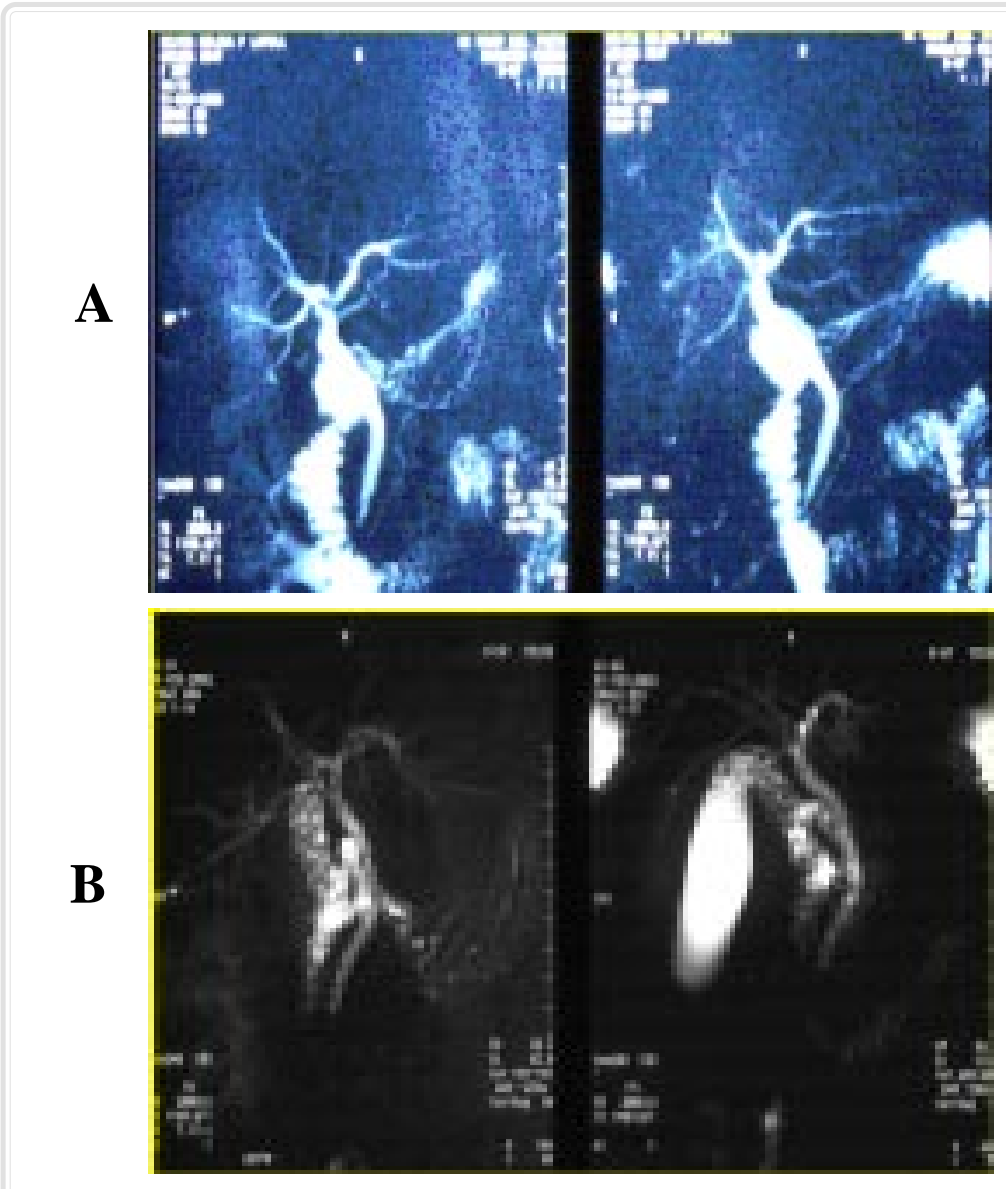

Figura 8 - Colangiografia por ressonância magnética (CPRM). Os pacientes apresentavam PA biliar branda e colestase. Em (A), a via biliar está normal e, em (B), existem múltiplos cálculos na vesícula e alguns no colédoco distal. Fonte: CCIFM-HC-FMRP-USP 
RM demonstra os mesmos achados na PA, quando comparada à TC, o que é exemplificado na Figura 9.

A definição etiológica das afecções agudas das vias biliares que podem cursar com hiperamilasemia, tais como, colangite e colecistite aguda e a PA pode ser difícil. Todavia, tal diferenciação, na maioria das vezes, não é essencial, porque, na maioria dos casos, a evolução inicial é satisfatória com o tratamento clínico ${ }^{(2,8)}$.

Quando a evolução é desfavorável e os exames menos invasivos, como a US e a RM, não
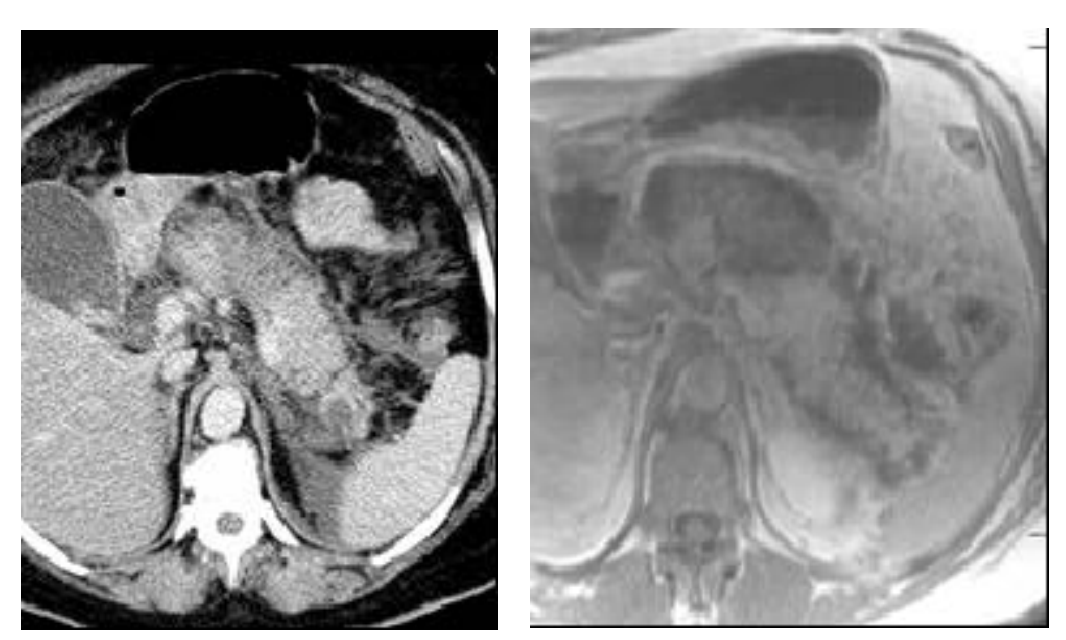

Figura 9 - PA biliar. Exemplo de necrose pancreática na TC e na RM. Fonte: CCIFM-HC-FMRP-USP estão disponíveis ou não permitem avaliar com precisão as vias biliares, a colangiografia, por via endoscópica, tem indicação diagnóstica e, eventualmente, terapêutica. Se verificada presença de litíase nas vias biliares, em geral, procede-se à drenagem e ou à esfincterotomia endoscópica com a retirada de cálculos ${ }^{(8)}$.

Os riscos potenciais desses procedimentos invasivos são a exacerbação da PA e a infecção pancreática pela injeção de contraste não estéril, em tecido necrótico, o que justifica a relutância e o rigor no critério para a indicação da CPRE na $\mathrm{PA}^{(8)}$.

\section{ESTRATIFICAÇÃO DA DOENÇA}

Vários grupos de critérios prognósticos da PA ou marcadores isolados são utilizados: Critérios de Ranson ${ }^{(26)}$, a dosagem da proteína $\mathrm{C}$ reativa ${ }^{(27)}$, os critérios do APACHE II ${ }^{28}$, os critérios tomográficos de Balthazar e colaboradores ${ }^{(29)} \mathrm{e}$, mais recentemente, a classificação de $\operatorname{Atlanta}^{(7)}$.

Ranson e colaboradores identificaram 11 sinais precoces de prognóstico ruim para a pancreatite alcoólica ${ }^{(26)}$ e biliar $^{(30)}$, sendo cinco obtidos por ocasião da internação e seis que são verificados durante as primeiras $48 \mathrm{~h}$ (Tabela IV).

Para os pacientes com dois ou menos fatores, a mortalidade é muito baixa, ao passo que o índice atinge $15 \%$, quando mais de três desses sinais estão presentes; ele-

\section{Tabela IV - Critérios múltiplos de Ranson.}

\begin{tabular}{|l|c|c|}
\hline Avaliação & $\begin{array}{c}\text { Pancreatite } \\
\text { Alcoólica }\end{array}$ & $\begin{array}{c}\text { Pancreatite } \\
\text { Biliar }\end{array}$ \\
\hline POR OCASIÃO DA ADMISSÃO & & \\
\hline 1. Idade (anos) & $>55$ & $>70$ \\
\hline 2. Glicose (mg/dl) & $>200$ & $>220$ \\
\hline 3. Leucócitos & $>16.000$ & $>18.000$ \\
\hline 4. Desidrogenase lática (UI/l) & $>350$ & $>400$ \\
\hline 5. Aspartato transferase (UI/l) & $>250$ & $>250$ \\
\hline NAS 48 H INICIAIS & $>10$ & $>10$ \\
\hline 1. Queda do hematócrito & $<8$ & $<8$ \\
\hline 2. Cálcio sérico (mg/dl) & $>4$ & $>5$ \\
\hline 3. Défice de base (mEq/l) & $>5$ & $>2$ \\
\hline 4. Aumento do N $\mathrm{N}_{2}$ urinário (mg/dl) & $>6$ & - \\
\hline 5. Seqüestração hídrica (l) & $<60$ & \\
\hline 6. pO (mmHg) & & \\
\hline
\end{tabular}

va-se para cerca de $40 \%$ nos pacientes com cinco ou seis sinais, e aproxima-se de $100 \%$ nos pacientes com sete ou oito sinais.

O Sistema de APACHE II, que se baseia no índice ponderado de 12 variáveis fisiológicas, dados clínicos e laboratoriais, é capaz de fornecer discriminação útil entre ataques de PA branda e grave, em 
poucas horas após a admissão do paciente. $\mathrm{O}$ escore de APACHE II é mais sensível e específico (75\% e $92 \%)$ do que os critérios de Ranson (75\% e 68\%) na previsão da gravidade e das complicações, $48 \mathrm{~h}$ após a admissão ${ }^{(28)}$.

A proteína $\mathrm{C}$ reativa é o marcador mais utilizado isoladamente, é barato e fácil de ser dosado e o nível normal é de até $10 \mathrm{mg} / \mathrm{l}$. Os níveis acima de $150 \mathrm{mg} / \mathrm{l}$ são muito sugestivos de necrose pancreática ${ }^{(27)}$.

Balthazar e colaboradores ${ }^{(29,31)}$ analisaram o valor prognóstico da TC realizada mediante contraste intravenoso com infusão em bolo. Na fase inicial da PA, idealizaram um índice de gravidade com base na avaliação dos achados tomográficos (Tabela V).

Na prática clínica, os critérios prognósticos apresentados são pouco utilizados, sobretudo em virtude da complexidade, todavia têm sua utilidade na padronização das amostras em estudos controlados.

A dicotomia, já mencionada na história natural da PA levou o Simpósio de Atlanta ${ }^{(7)}$ a classificar a pancreatite em branda e grave.

A PA branda é intersticial e edematosa e está associada à disfunção orgânica mínima e à recuperação completa.

Na forma grave, há disfunção sistêmica. Nos primeiros dias, podem ocorrer disfunções renal, cardiovascular, respiratória, hematológica, neurológica e disfunção do metabolismo hídrico, eletrolítico e acidobásico; a sepse, em geral, desenvolve-se no fim da primeira semana e agrava as disfunções já mencionadas. As alterações sistêmicas, em geral, são acompanhadas de complicações locorregionais no pâncreas (necrose, hemorragia e coleções peripancreáticas). As lesões pancreáticas e peripancreáticas podem regredir ou evoluir com infecção da necrose, formação de abscessos, ascite pancreática e pseudocisto.

A avaliação clínica inicial permite, na grande maioria das vezes, a separação dos pacientes com a forma de apresentação em PA branda e grave. As insuficiências orgânicas manifestam-se nos primeiros dias do episódio de PA. Acredita-se que a PA grave não evolui a partir da PA branda. A classificação de Atlanta é simples e prática. Aponta, precocemente, os casos graves, determinando a necessidade de monitoramento invasivo, de cuidados intensivos e de exames de imagem.

\section{Tabela V - Critérios tomográficos de Balthazar}

\section{Pontos}

Graus da Pancreatite

aumento do pâncreas

inflamação pancreática e peripancreática $\quad 2$

uma coleção líquida $\quad 3$

duas ou mais coleções líquidas $\quad 4$

Graus de Necrose Pancreática

- necrose de $1 / 3$ do pâncreas $\quad 2$

necrose de $1 / 2$ do pâncreas $\quad 4$

necrose de mais de $1 / 2$ do pâncreas $\quad 6$

ndice (no de pontos) Complicação (\%) Mortalidade (\%)

\begin{tabular}{|c|c|r|}
\hline 0 a 1 & 0 & 0 \\
\hline 2 e 3 & 8 & 3 \\
\hline 4 a 6 & 35 & 6 \\
\hline 7 a 10 & 92 & 17 \\
\hline
\end{tabular}

Há correspondência entre o índice obtido com a morbidez e a mortalidade.

\section{TRATAMENTO CLÍNICO}

Não há tratamento específico para o processo inflamatório, que impeça a progressão da doença. Assim, o tratamento, na fase inicial, é clínico e sintomático. A cirurgia é indicada para resolver algumas condições associadas, com o objetivo de prevenir novos episódios e tratar as complicações locais (necrose infectada, abscessos, fístulas e pseudocistos). As complicações da PA podem ser decorrentes da toxicidade sistêmica, associadas à falência de múltiplos órgãos, ou podem refletir os eventos patológicos, confinados ao pâncreas e aos tecidos peripancreáticos. Uma classificação temporal, em complicações de natureza precoce, intermediária e tardia, pode auxiliar na abordagem terapêutica ${ }^{32}$ (Tabela VI).

A abordagem inicial, na PA, é centrada na obtenção da estabilidade clínica, independente da etiologia e da gravidade da doença. Concomitantemente, esforços são feitos no sentido de estratificar a gravidade da PA, diagnosticar e tratar, se for o caso, a etiologia, assim como as complicações da doença. O seqüestro de fluidos para o terceiro espaço pode ultrapassar um terço do volume plasmático, o que pode desencadear 
Tabela VI - Complicações da pancreatite aguda

1- Precoce, dois a três dias: manifestações cardiovasculares, pulmonares, renais e metabólicas

2- Interme diária, duas-cinco semanas: manifestações locais (infecção da necrose pancreática e retroperitoneal, abscesso, pseudocistos), complicações gastrintestinal, biliar e de órgãos sólidos

3- Tardia, meses a anos: ascite pancreática e complicações vasculares hemorrágicas

insuficiência renal em cerca de $20 \%$ dos casos, e cursar com taxas elevadas de mortalidade ${ }^{(32)}$. A restauração e a manutenção do volume de fluidos intravasculares pode demandar a infusão de 300 a $500 \mathrm{ml} / \mathrm{h}$ de soluções cristalóides, e requer controle simultâneo com correção dos distúrbios eletrolíticos e acidobásicos. Quando o choque decorre da síndrome da resposta inflamatória sistêmica e não há resposta a essa reposição, preconiza-se o uso de aminas vasoativas.

Os monitoramentos respiratório, cardiovascular e renal são fundamentais, porque, é a fase em que a descompensação cardiovascular é a principal causa de morte ${ }^{(33)}$. Os pacientes com PA grave necessitam, no mínimo, de cateter venoso periférico, cateter venoso central e sonda vesical. O cateter de Swan-Ganz, para mensurar a pressão encunhada na artéria pulmonar, o débito cardíaco e a resistência vascular periférica, está indicado aos pacientes que não respondem ao tratamento inicial ou que apresentam comprometimento cardiorrespiratório ${ }^{(34)}$.

Associado à reposição de fluidos, o tratamento da PA inclui o jejum até que as náuseas, os vômitos e a dor abdominal desapareçam. A elevação das enzimas pancreáticas sem sintomas não justifica o jejum prolongado e o suporte nutricional. A aspiração nasogástrica não está indicada rotineiramente; é empregada na vigência de náuseas e vômitos ou íleo adinâmico, mantido com grande distensão abdominal. Embora o jejum e a sucção gástrica sejam indicados, com o objetivo de evitar o estímulo da função exócrina e o aumento das enzimas proteolíticas, há estudos comparativos, envolvendo pacientes com PA aguda branda, que não demonstram o benefício com o jejum e a sucção gástrica prolongada ${ }^{(35,36)}$. O emprego de drogas anti-secretoras (bloqueadores $\mathrm{H}_{2}$, anticolinérgicos, glucagon, somatostatina) e o suporte nutricional, na PA branda, apresentam resultados conflitantes e não devem ser incorporados à rotina terapêutica.

Por outro lado, na PA grave, há o estado hiper- catabólico com resposta inflamatória sistêmica e deterioração do estado nutricional, e o suporte nutricional parenteral tem sido, há muito tempo, preconizado como fonte exógena de nutrientes para os pacientes $\left({ }^{37,38)}\right.$. Embora existam vários estudos comparando o suporte nutricional enteral com o parenteral e demonstrando que o primeiro é seguro, pode ser prescrito, no estágio precoce da doença, é quatro vezes mais barato, reduz a incidência de complicações sépticas e metabólicas e não tem efeitos adversos sobre a PA e o paciente ${ }^{(39,40,41)}$, a conclusão da revisão desses estudos, com base na evidência, ainda aponta que são insuficientes sobre os efeitos na história natural da doença ${ }^{(42)}$. A nutrição parenteral total ainda é a opção para pacientes com pancreatite grave acompanhada de íleo adinâmico e obstrução duodenal ${ }^{(21)}$.

A dor pode ser controlada pela administração de analgésicos, principalmente, meperidina, que tem menos interferência nas funções do esfíncter de Oddi, quando comparada à morfina.

A antibioticoterapia de rotina não é necessária na forma branda da PA. Entretanto, nas formas graves, nos casos que evoluem com pancreatite necrosante, nos pacientes idosos e nos imunossuprimidos, o emprego de antibióticos, que atinjam germes entéricos e anaeróbios, está indicado. Um estudo feito por meio de metanálise demonstrou benefício da antibioticoterapia profilática, em termos de redução de mortalidade $^{(43)}$. A infecção ocorre em 30 a $40 \%$ dos pacientes que apresentam mais que $30 \%$ de necrose do parênquima pancreático, e as complicações infecciosas ocorrem em, aproximadamente, $80 \%$ dos óbitos $\left({ }^{15)}\right.$. Os germes mais freqüentemente isolados, numa série de trabalhos, são Escherichia coli (35\%), Klebsiella pneumoniae (24\%), Enterococcus sp (24\%), Staphylococcus sp (14\%) e Pseudomonas $s p(11 \%)^{(44)}$. Preconiza-se o emprego de antibióticos com boa penetração no tecido peripancreático, tais como o imipenem, ciprofloxacina, metronidazol, cefotaxima; os aminoglicosídios têm baixa penetração pancreática.

Apesar das evidências a favor da antibioticoterapia profilática na PA grave, há avaliação recente, recomendando a prescrição seletiva ${ }^{(45)}$. A antibioticoterapia profilática, com agentes de amplo espectro, altera a bacteriologia da infecção pancreática secundária, de germes coliformes, predominantemente, gramnegativos, para organismos gram-positivos, ${ }^{(46)}$ e pode aumentar a incidência de infecção fúngica e a taxa de mortalidade ${ }^{(47)}$. Assim, a antibioticoterapia profilática deve ser prescrita para as PA graves e por um período curto de cinco a sete dias ${ }^{(21)}$. 
Os pacientes com insuficiência respiratória necessitam de intubação oro-traqueal e ventilação controlada, com pressão positiva no final da respiração (PEEP). O diagnóstico precoce e o tratamento adequado de tal complicação melhoram muito o prognóstico. A insuficiência renal secundária pode ser evitada com a reposição de líquiidos; todavia, outros fatores tóxicos podem comprometer a função renal. $\mathrm{O}$ tratamento é idêntico ao da necrose tubular aguda, que se desenvolve em qualquer situação: restrição hídrica, correção dos distúrbios eletrolíticos e da aci-dose metabólica. A hemodiálise e a diálise peritoneal, contínua podem ser necessárias ${ }^{(2,8)}$.

\section{TRATAMENTO CIRÚRGICO}

Enquanto os efeitos sistêmicos da PA são tratados clinicamente, as condições associadas e as lesões locorregionais são os principais focos de interesse cirúrgico. Em geral, a intervenção cirúrgica está indicada para os pacientes que apresentam necrose pancreática infectada e complicações peripancreáticas (abscesso, perfuração ou obstrução de vísceras, hemorragia, pseudocistos, dentre outras), e para tratar a doença biliar, como condição associada.

O diagnóstico precoce da necrose infectada é importante e pode ser aventado, quando a dor for contínua e progressiva, associada à febre e leucocitose e/ ou à falência de órgãos. Todavia, o padrão clínico e o laboratorial de ambas as formas, estéril ou infectada, geralmente, são semelhantes ${ }^{(48)} \mathrm{e}$ a TC revela o padrão de bolhas de ar em apenas 20 a $25 \%$ dos pacientes com abscesso pancreático. Então, a diferenciação entre necrose estéril e infectada só pode ser confirmada mediante cultura de material necrótico e das coleções fluidas, que podem ser colhidos por meio de punção percutânea, guiada por US ou tomografia ${ }^{(48,49)}$, conforme algorítimo $^{(21)}$ (Figura 10).

O desbridamento cirúrgico, precoce, da necrose pancreática, seguido de reintervenções programadas, está sendo, gradualmente, substituído pela abordagem cirúrgica retarda- da, que tem se tornado seletiva, orientada pela presença da falência orgânica e do aparecimento de infecção. O desbridamento cirúrgico da necrose pancreática estéril não previne ou melhora a falência orgânica já instalada. Ademais, aumenta o risco de infecção e há indícios de aumento das complicações e das taxas de mortalidade ${ }^{(50,51)}$. Por outro lado, o desbridamento cirúrgico convencional e a drenagem da loja pancreática são as abordagens indicadas para a necrose pancreática infectada, apesar de relatos ocasionais, de tratamento bem sucedido com a drenagem percutânea ou endoscópica ${ }^{(52,53)}$.

$\mathrm{Na}$ operação precoce, considerada assim antes da segunda semana, o paciente, em geral, está instável e, durante o procedimento, não se consegue delimitar, com precisão, as áreas com tecido desvitalizado. Considerando que a contaminação do tecido necrótico por bactérias, raramente, ocorre na primeira semana, há subsídio para, em princípio, evitar-se a operação precoce na PA com necrose. Após duas semanas, o paciente, em geral, está mais estável e a identificação do limite entre o tecido necrótico e o normal é mais fácil. O tecido necrótico, já amolecido, é mais facilmente destacável do tecido viável mediante desbridamento, o que favorece a preservação do parênquima funcionante. Além da abordagem do pâncreas, todo o espaço retroperitoneal, mediante mobilização dos cólons direito e esquerdo, deve ser pesquisado, para a remoção dos focos de necrose $e^{(2,7)}$.

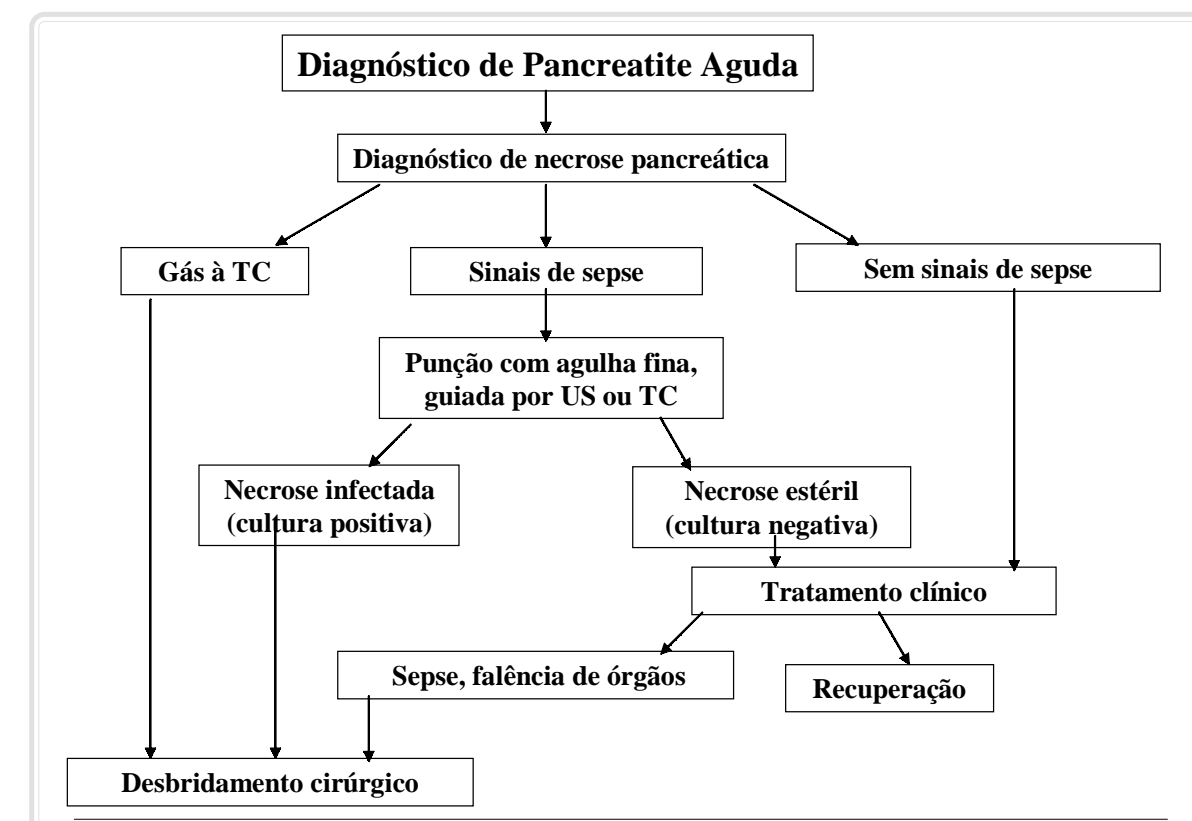

Figura 10 - Algoritmo para Tratamento da Necrose Pancreática Modificado de Yousaf M. Br J Surg 90: 404-420, 2003(21) 
A modalidade de abordagem cirúrgica da PA com necrose infectada ainda não é consenso, todavia, a ressecção pancreática, parcial ou total, praticada por muitos anos, não é recomendada, porque se acompanha de taxas elevadas de mortalidade e morbidade ${ }^{(54,55)}$. O tratamento correntemente empregado é a necrosectomia do parênquima pancreático e da gordura retroperitoneal por meio da separação digital do tecido desvitalizado. Após o desbridamento, deve ser feita a lavagem exaustiva da cavidade peritoneal com vários litros de solução salina até que a superfície dos tecidos pancreáticos e peripancreáticos esteja limpa. $\mathrm{Na}$ seqüência, procede-se a hemostasia cuidadosa, eventualmente, empregando pontos de transfixação. A loja pancreática e o espaço retroperitoneal devem ser drenados. A comparação entre relaparotomia convencional e laporostomia após necrosectomia não evidencia diferença nas taxas de morbidade e mortalidade ${ }^{(56)}$.

Com a melhora dos cuidados intensivos, incluindo a antibioticoterapia profilática, a intervenção cirúrgica, na PA com necrose infectada, geralmente, não tem sido realizada na fase precoce, o que facilita a necrosectomia, reduz o número de reoperações ${ }^{(51)}$ e a doença pode ser controlada com uma única operação, em cerca de $80 \%$ dos $\operatorname{casos}^{(57)}$.

Na PA biliar branda, após regressão das manifestações inflamatórias, indica-se a colecistectomia com exploração das vias biliares, o que, habitualmente, é feito na mesma internação, entre o $5^{\circ}$ e o $7^{\circ}$ dias após o início da doença pancreática. Na PA biliar grave, a colecistectomia deve ser retardada até a solução da resposta inflamatória e da recuperação clínica. Nos pacientes idosos, com risco cirúrgico elevado, a esfincterotomia endoscópica pode ser considerada a terapêutica definitiva ${ }^{58)}$. As condições associadas à PA, ou decorrentes de suas complicações, que necessitam monitoramento e, eventualmente, intervenção estão no algoritmo da Figura $11^{(59)}$.

\section{CONCLUSÃO}

Nos últimos anos, ocorreram mudanças significativas na abordagem diagnóstica e no tratamento da PA. As recomendações principais, baseadas na revisão da literatura, podem ser resumidas como a seguir $^{(8,11,21)}$ : A classificação da doença em branda e grave é fundamental para o planejamento terapêutico. O suporte nutricional, se possível enteral, deve ser introduzido precocemente, na PA grave. O papel da antibioticoterapia profilática permanece controverso, mas há o consenso geral de que é benéfico na PA grave; todavia, deve ser de amplo espectro e prescrito por período curto. Todos os pacientes com PA grave devem ser submetidos à tomografia ou RM para detecção de necrose. As colangiografias por ressonância e endoscópica estão indicadas, respectivamente, para diagnóstico e terapêutica, nos pacientes com obstrução biliar e colangite. A punção com agulha fina, guiada por US ou tomografia, para exame bacteriológico e cultura, deve ser realizada, para diferenciar a necrose pancreática estéril da infectada. A necrose infectada, diagnosticada pela presença de bolhas gasosas à tomografia ou pela cultura positiva, deve ser tratada por meio da necrosectomia cirúrgica. A necrose estéril deve ser tratada clinicamente, a menos que haja deterioração progressiva para sepse ou disfunção de múltiplos órgãos. Há consenso de que é melhor evitar, sempre que possível, fazer o tratamento cirúrgico precoce, todavia não há consenso sobre os procedimentos a serem realizados e o momento das intervenções. Pacientes com PA biliar devem ser submetidos à colecistectomia; o momento da operação depende da gravidade da doença (precoce para forma branda e tardio para a forma grave da PA).

A Associação Internacional de Pancreatologia, em $2002^{(58)}$ fez 11 recomendações com base em evidências científicas, para orientação na abordagem da PA e avaliação da qualidade assistencial prestada aos doentes:

1) O tratamento da PA branda é clínico.

2) A antibioticoterapia de largo espectro reduz as taxas de infecção na PA com necrose, mas parece não melhorar a sobrevida.

3) A punção com agulha fina, para exame bacteriológico, deve ser realizada para diferenciar a necrose pancreática estéril da infectada, nos pacientes com quadro de sepse.

4) Pacientes que apresentam sinais e sintomas de sepse e necrose pancreática infectada têm indicação de intervenção cirúrgica ou drenagem radiológica.

5) Pacientes com necrose pancreática estéril, confirmada à punção e bacteriologia por meio de agulha fina, podem ser tratados clinicamente; a intervenção cirúrgica é indicada em situações específicas.

6) A operação precoce, nos 14 dias após o início da doença, não é recomendada nos pacientes com necrose pancreática, a menos que haja alguma condição específica.

7) A operação e outros procedimentos devem incluir a necrosectomia com a remoção de todos os debris e coleções do retroperitônio e ter como meta a pre- 


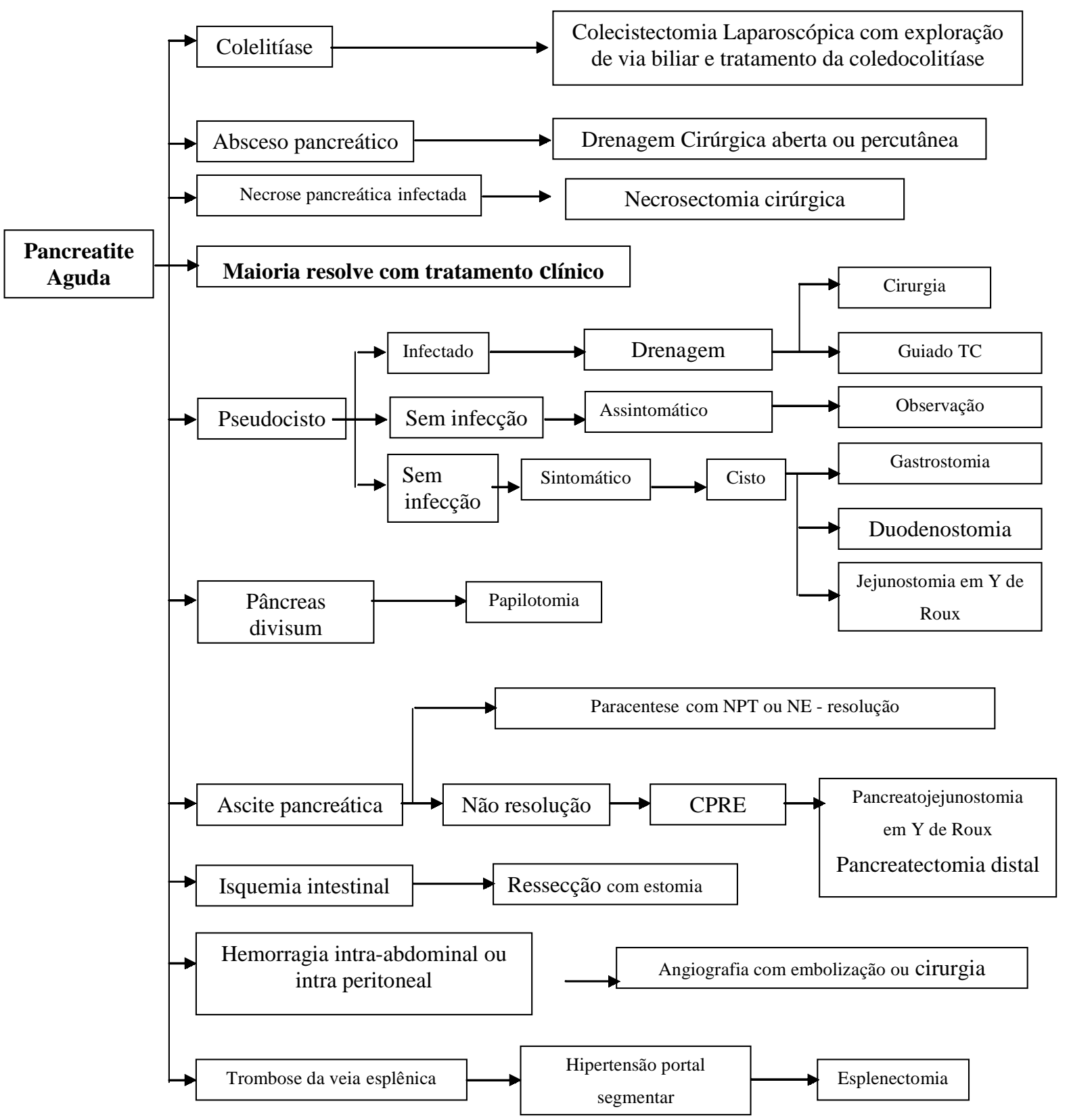

Figura 11 - Algorítimo para tratamento da Pancreatite Aguda. CT: tomografia computadorizada. CPRE: colangiopancreatografia retrógrada endoscópica. NPT: nutrição parenteral total. NE: Nutrição enteral.

Modificado de Aranha G V. Acute pancreatitis: In Rakel: Conn's. Current Therapy 56 $6^{\text {th }}$ ed, Elsevier, New York, p.564-568, 2004 (59)

servação do pâncreas.

8) Na PA biliar, a colecistectomia deve ser realizada para evitar a recorrência da doença.

9) Na PA biliar branda, a colecistectomia deve ser realizada assim que o paciente recuperar-se, e de preferência na mesma internação.
10) Na PA biliar grave, a colecistectomia deve ser retardada, até que haja resolução da resposta inflamatória e recuperação clínica.

11) A papilotomia endoscópica é uma alternativa à colecistectomia, nos pacientes com PA biliar e risco cirúrgico elevado. 
SANTOS JS; ELIAS JÚNIOR E; SCARPELINI S \& SANKARANKUTTY AK. Acute pancreatitis: review of concepts and management. Medicina, Ribeirão Preto, 36: 266-282, apr./dec. 2003.

ABSTRACT - The guidelines for management of acute pancreatitis (AP) have changed significantly over the past 20 years, especially regarding the surgical treatment of severe cases. $A$ review of the literature shows the importance of trying to assess the severity of AP as well as its early complications in order to plan the supportive care. Recent evidence has helped to clarify the roles of computerized tomography, endoscopic retrograde cholangiopancreatography, magnetic resonance, prophylactic antibiotics, enteral feeding and fine-needle aspiration bacteriology in the management of acute pancreatitis. This has been a change away from the early aggressive surgical intervention towards more conservative management, except when infected necrosis is confirmed. The guidelines recommend the early detection and objective evaluation of complications by clinical and imaging techniques. A formal approach with the appropriate use of various non-surgical and surgical options can help the ongoing attempts at decreasing mortality and morbidity in AP.

UNITERMS - Pancreatitis, Acute. Pancreatitis. Monitoring. Pancreatitis; Acute Necrotizing. Nutrition; surgery; treatment.

\section{REFERÊNCIAS BIBLIOGRÁFICAS}

1 - TOOLI J; BROOKE-SMITH M; BASSI C; CARR-LOCKE D; TELFORD J; FREENY P; IMRIE C \& TANDON R. Guidelines for management of acute pancreatites. J Gastroenterol Hepatol 17: 15-39, 2002. Suppl

2 - CENEVIVA R; SANTOS JS; ANDRADE JI \& SILVA Jr OC. Pancreatite aguda. Medicina, Ribeirão Preto 28: 701-721, 1995

3 - MANN DV; HERSHMAN MJ; HITTINGER R \& GLAZER G. Multicentre audit of death from acute pancreatitis. Br J Surg 81: 890-893, 1994

4 - MUTINGA M; ROSENBLUTH A; TENNER SM; ODZE RR; SICA GT \& BANKS PA. Does mortality occur early or late in acute pancreatitis? Int J Pancreatol 28: 91-95, 2000

5 - STEER ML. How and where does acute pancreatitis begin? Arch Surg 127: 1350-1353, 1992

6 - NIEUWENHUIJS VB; BESSILINK MG; VAN MINNEM LP \& GOOSZEN HG. Surgical management of acute necrotizing pancreatitis: a 13-year experience and a systematic review. Scand J Gastroenterol 239:111-116, 2003. Suppl.

7 - BRADLEY EL. III. A clinically based classification system for acute pancreatitis: Summary of the International Symposiun of Acute Pancreatitis. Arch Surg 128: 586-590, 1993.

8 - FERREIRA-SANTOS R \& SANTOS JS. Pancreatite aguda 19402000: Evolução de conceitos e condutas In: FEDERAÇÃO BRASILEIRA DE GASTROENTEROLOGIA. A Gastroenterologia do Brasil. Ed. Revinter, Rio de Janeiro, p. 269-290, 2001.

9 - BEGER HG \& ISENMANN R. Diagnosis, objective, assessment of severity, and management of acute pancreatitis. Santorini Consensus Conference. Int J Pancreatol 26:1-2, 1999.

10 -SOCIETE NATIONALE FRANÇAISE DE GASTROENTEROLOGIE. [Consensus conference: Acute pancreatitis]. Gastroenterol Clin Biol 25: 177-192, 2001.

11 - ELIAS JÚNIOR J. Utilização da tomografia computadorizada sem contraste e da ressonância magnética no diagnóstico e estratificação da gravidade da pancreatite aguda. Tese de
Doutorado, Faculdade de Medicina de Ribeirão Preto da USP, Ribeirão Preto. p.1-117, 2002.

12 - BECKNGHAM $J$ \& BORNMAN PC. ABC of disesases of liver,pancreas, and biliary system. acute pancreatitis. BMJ 322 (7286): 595-598, 2001

13 - LANKISCH PG; SCHIRREM CA \& KUNZE E. Unselected fatal pancreatitis: Why is the disease so frequently overlooked? Am J Gastroenterol. 86: 322-326,1991.

14 - RANSON JHC. Acute pancreatitis. In: LENINE BA; COPELAND ME; HOWARD RJ; SUGERMAN HJ \& WARSHAW AL. Current practice of gastrointestinal and abdominal surgery. Churchill Livingstone, New York, p.1-29, 1994.

15 - BEGER HG; RAU B \& MR JPRALLE U. Natural course of pancreatitis. World J Surg 21: 130-135,1997.

16 - DENHAM W \& NORMAN J. The potencial role of therapeutic cytocine manipulation in acute pancreatitis. Surg Clin North Am 79: 767-781, 1999.

17 - KOLAR JC; ELLIS CJ \& HEVITT MD. Comparison of serum amylase pancreatic isoamylase and lipase in patients with hyperamylasemia. Dig Dis Sci 29: 289-293, 1984.

18 - MCKAY AJ; IMRIE CW; O'NEIL J \& DUNCAN JG. Is an early ultrasound scan of value in acute pancreatitis? Br J Surg 69: 369-372 1982.

19 - BENNETT GL \& BALTHAZAR EJ. Imaging of acute and chronic pancreatitis. In: MUELLER PR, ed. Hepatobiliary and pancreatic radiology: Imaging and intervention. Thieme Medical Publishers, New York, p. 746-782, 1998.

20 - BENNETT GL \& HANN LE. Pancreatic ultrasonography. Surg Clin North Am 81: 259-281, 2001.

21 - YOUSAF M; MCCALLION K \& DIAMOND T. Management of acute pancreatitis. Br J Surg 90: 407-420, 2003.

22 - DERVENIS C; JOHNSON CD; BASSI C; BRADLEY E; IMRIE CW; MCMHON MJ \& MODLIN I. Diagnosis, objective assessment of severity, and management of acute pancreatitis. Santorini consensus conference. Int J Pancreatol 25: 195-210. 1999. 
23 - DE BEAUX AC; CARTER DC \& PALMER KR Endoscopic retrograde cholangiopancreatography anda acute pancreatitis. Gut 38: 799-800, 1996.

24 - SITIRIS MG; TENNOE B; AADLAND E \& LUNDE C. MR cholangiopancreaticography and endoscopy retrograde cholangiopancreatography in patients with suspected common bile duct stones. Acta Radiol 41: 269-272, 2000.

25 - WERNER J; SCHIMIDT J; WARSHAW AL; GEBBARD MM; HERFARTH C \& KLAR E. The relative safety of MRI contrast agent in acute necrotizing pancreatitis. Ann Surg 227: 105111,1998 .

26 - RANSON HJC; RIFKIND KM; ROSES DF; FINK SD; ENG K \& SPENCER FC. Prognostic sings and the role of operative management in acute pancreatitis. Surg Gynaecol Obstet 139: 69-81, 1974.

27. PUOLAKKAINEN P; VALTONEN V; PAANANEN A \& SCHRODER T. C-reactive protein (CRP) and serum phospholipase $A_{2}$ in the assessment of the sevevity of acute pancreatitis. Gut 28: 764-771, 1987.

28 - LARVIN M \& MAC MAHON MD. APACHE II Score for assessment and monitoring of acute pancreatitis. Lancet 2: 20129, 1989.

29 - BALTHAZAR EJ; ROBINSON DL; MEGIBOW AJ \& RANSON JHC. Acute pancreatitis: Value of CT in establishing prognosis. Radiology 174: 331-336, 1990.

30 - RANSON HJC. The timing of biliary surgery in acute pancreatitis. Ann Surg 189: 654-662, 1979.

31 - BALTHAZAR EJ. Complicatons of acute pancreatitis: Clinical and CT evaluation. Radiol Clin North Am 40: 1211-1227, 2002.

32 - FREY C. Pathognesis of nitrogen retention in pancreatitis. Am J Surg 109: 747-755, 1965.

33 - PITCHUMONI CS; AGARWAL N \& JAIN NK. Sistemic complications of acute pancreatitis. Am J Gastroenterol 83: 597-606, 1988

34 - BRITSH SOCIETY OF GASTROENTEROLOGY. United kingdom guidelines for the management of acute pancreatitis. Gut 42: S1-S13, 1998. Suppl. 2.

35 - LEVANT JA; SECRIST DM; RESIN H; STUDERVANT RA \& GUTH PH. Nasogastric suction in the treatment of alcholic pancreatitis. A control study. JAMA 229: 51-52,1974.

36 - NACIJE R; SALINGRET E; CLUMECK N De TROYER A \& DEVIS G. Is nasogastric suction necessary in acute pancreatitis? BMJ II: 659-660,1978.

37 - GOODGAME JT \& FISCHER JE. Parenteral nutrition in the treatment of acute pancreatitis:effect on complications and mortality. Am Surg 186: 651-658,1977.

38 - GRANT JP; JAMES S; GRABOWSKI V \& TREXLER KM. Total parenteral nutrition in pancreatic disease. Ann Surg 200: 627-631,1984.

39 - KALFARENTZOS FE; KARAVIAS DD; KARATZAS TM; ALEVIZATOS BA \& ANDROULAKIS JA. Total parenteral nutrition in severe acute pancreatitis. J Am Coll Nutr 10: 156-162, 1991.

40 - MCCLAVE SA; SNIDER H; OWENS N \& SEXTON LK. Clinical nutrition in pancreatitis. Dig Dis Sci 42: 2035-2044, 1997.

41 - WINDSOR AC; KANWAR S; LI AG; BARNES E; GUTHRIE JA; SPARK JI; WELSH F; GUILLOU PJ \& REYNOLDS JV. Compared with parenteral nutrition, enteral feeding attenuates the acute phase response and improves disease severity in acute pancreatitis. Gut 42: 431-435, 1998.
42 - EVIDENCE-BASED SURGERY. J Am Coll Surg 195, 865, 2002.

43 - GOLUB R; SIDDIQI F \& PHOL D. Role of antibiotics in acute pancreatitis: a meta-analysis. J Gastrointest Surg 2: 496503,1998

44 - LUMSDEN A \& BRADLEY III EL. Secondary pancreatic infections. Surg Gynecol Obstet $170: 459-467,1990$

45 - ISENMANN R; NZI RM; KRON M; KAHL S; KRAUS D; JUNG N; MAIER L; MALFERTHEINER P; GOEBELL H \& BEGER HG. Prophylactic antibiotic treatment in patients with predicted severe acute pancreatitis: A placebo-controlled, double-blind trial. Gastroenterology 127: 997-1004, 2004.

46 - HOWARD TJ \& TEMPLO MB. Prophylatic antibiotics alter the bacteria infected necrosis in severe acute pancreatitis $\mathbf{J}$ Am Coll Surg 195: 759-767, 2002.

47 - EATOCK FC; BROMBACKER GD; HOOD J; CARTER CR \& IMRIE $\mathrm{CW}$. Fungal infection of pancreatic necrosis is associated with increased mortality. Br J Surg 86: 78, 1999. Suppl. II.

48 - RAU B; UHL W; BUCHLER MW \& BEGER HG. Surgical treatment of infected necrotizing pancreatitis World J Surg 21: 155-161,1997.

49 - RAU B; PRALLE U; MAYER JM \& BEGER HG. Role of ultrasographically guided fine-needle aspiration cytology in the diagnosis of infected pancreatic necrosis. $\mathbf{B r} \mathbf{J}$ Surg 85:179-184,1998.

50 - MIER J; LEON E.L; CASTILLO A; ROBLEDO F \& BLANCO R. Early versus late necrosectomy in severe necrotizing pancreatitis. Am J Surg 173: 71-75,1997

51 - HUNGNESS ES; ROBB BW; SECSKIN C; HASSELGREN PO \& LUCHETTE FA. Early debridement for necrotizing pancreatitis: is it worthwhile? J Am Coll Surg 194: 740-744, 2002.

52 - BRADLEY EL III. Acute Pancreatitis. Assessment and treatment of severe acute pancreatitis. Digestion 60: 19-21, 1999. Suppl. 1.

53 - BEGER HG; BÜCHLER M; BITTNER R; BITTNER R; OETTINGER W \& BLOCK S. Necrosectomy and postoperative local lavage in patients with necrotizing pancreatitis. Results of a prospective clinical trial. World J Surg 12: 255-262, 1988.

54 - WILSON C; MCARDLE CS; CARTER DC \& IMRIE CW. Surgical treatment of acute necrotizing pancreatitis. Br J Surg 154: 1119-1123,1988

55 - NORDBACK IH \& AUVINEN AO. Long-term results after pancreas resection for acute necrotizing pancreatitis. Br J Surg 72: 687-689,1985

56 - TZOVARSA G; PARKS RW; DIAMOND T \& ROWLANDS BJ. Early and log-term results after necrosectomy for necrotizing pancreatitis. Br J Surg 86: 417, 1999

57 - HARTWIG W; WERNER J; MULLER CA; UHL W \& BUCHLER MW. Surgical management of severe pancreatitis including sterile necrosis. J Hepatol Biliary-Pancreatic Surg 9: 429-435,2002

58 - UHL W; WARSHAW A; IMRIE C; BASSI C; MCKAY CJ; LANKISCH PG; CARTER R; DI MAGNO E; BANKS PA; WHITCOMB DC; DERVENIS C; ULRICH CD; SATAKE K; GHANEH P; HARTWIG W; WERNER J; MCENTEE G; NEOPTOLEMOS JP \& BÜCHLER MW. IAP guidelines for the surgical management of acute pancreatitis. Pancreatology 2: 565-573, 2002

59 - ARANHA GV. Acute pancreatitis. In: RAKEL RE. Conn's current therapy, $56^{\text {th }}$ ed, Elsevier, New York, p. 564-568, 2004. 